\title{
Diagnostic value of radiomics and machine learning with dynamic contrast-enhanced magnetic resonance imaging for patients with atypical ductal hyperplasia in predicting malignant upgrade
}

\author{
Roberto Lo Gullo ${ }^{1}$ Kerri Vincenti ${ }^{1}$. Carolina Rossi Saccarelli ${ }^{1}$. Peter Gibbs ${ }^{2}$. Michael J. Fox ${ }^{3}$. Isaac Daimiel ${ }^{1}$. \\ Danny F. Martinez ${ }^{1} \cdot$ Maxine S. Jochelson ${ }^{1} \cdot$ Elizabeth A. Morris ${ }^{1} \cdot$ Jeffrey S. Reiner ${ }^{1} \cdot$ Katja Pinker $^{1,4}$
}

Received: 29 October 2020 / Accepted: 23 December 2020 / Published online: 20 January 2021

(c) The Author(s) 2021

\begin{abstract}
Purpose To investigate whether radiomics features extracted from magnetic resonance imaging (MRI) of patients with biopsy-proven atypical ductal hyperplasia (ADH) coupled with machine learning can differentiate high-risk lesions that will upgrade to malignancy at surgery from those that will not, and to determine if qualitatively and semi-quantitatively assessed imaging features, clinical factors, and image-guided biopsy technical factors are associated with upgrade rate.

Methods This retrospective study included 127 patients with 139 breast lesions yielding ADH at biopsy who were assessed with multiparametric MRI prior to biopsy. Two radiologists assessed all lesions independently and with a third reader in consensus according to the BI-RADS lexicon. Univariate analysis and multivariate modeling were performed to identify significant radiomic features to be included in a machine learning model to discriminate between lesions that upgraded to malignancy on surgery from those that did not.

Results Of 139 lesions, 28 were upgraded to malignancy at surgery, while 111 were not upgraded. Diagnostic accuracy was $53.6 \%$, specificity $79.2 \%$, and sensitivity $15.3 \%$ for the model developed from pre-contrast features, and $60.7 \%, 86 \%$, and $22.8 \%$ for the model developed from delta radiomics datasets. No significant associations were found between any radiologistassessed lesion parameters and upgrade status. There was a significant correlation between the number of specimens sampled during biopsy and upgrade status $(p=0.003)$.

Conclusion Radiomics analysis coupled with machine learning did not predict upgrade status of ADH. The only significant result from this analysis is between the number of specimens sampled during biopsy procedure and upgrade status at surgery.
\end{abstract}

Keywords Radiomics $\cdot$ Machine learning $\cdot$ High-risk lesions $\cdot$ ADH $\cdot$ Atypical ductal hyperplasia

\section{Introduction}

Katja Pinker

pinkerdk@mskcc.org

1 Department of Radiology, Breast Imaging Service, Memorial Sloan Kettering Cancer Center, 300 E 66th Street, New York, NY 10065, USA

2 Department of Radiology, Memorial Sloan Kettering Cancer Center, 300 E 66th Street, New York, NY 10065, USA

3 Sloan Kettering Institute, Memorial Sloan Kettering Cancer Center, Mortimer B. Zuckerman Research Center, 417 E 68th Street, New York, NY 10065, USA

4 Department of Biomedical Imaging and Image-guided Therapy, Division of Molecular and Structural Preclinical Imaging, Medical University of Vienna, Waehringer Guertel 18-20, 1090 Vienna, Austria
With the widespread use of image-guided breast biopsies in clinical practice, lesions with uncertain potential of malignancy, also known as high-risk lesions, have become increasingly identified. Several types of high-risk breast lesions exist, with differing upgrade rates at subsequent surgical excisions [1-5]. Atypical ductal hyperplasia (ADH) is a type of high-risk proliferative breast lesion involving the terminal ductal lobular units of the breast and is a non-obligate precursor to invasive breast cancer. At image-guided biopsy, it is difficult to distinguish ADH from low-grade ductal carcinoma in situ (DCIS) [6]. The rate of upgrading ADH to DCIS or invasive cancer has been reported to be between 10 and $31 \%$ at a subsequent surgical excision [7]. 
In clinical practice, the two entities are distinguished pathologically based on quantitative criteria according to the World Health Organization classification of breast tumors [8]. Because the amount of atypia in the biopsy sample may be underestimated at image-guided biopsy, the National Comprehensive Cancer Network guidelines state that not only DCIS requires surgical excision but also ADH [9]. Nevertheless, the majority of ADH end up not being upgraded to malignancy based on surgical excision [10]. Accordingly, a pre-surgical non-invasive tool to identify women at low risk of an upgrade from ADH to DCIS or invasive cancer could serve to obviate surgery for these women, along with the unnecessary associated expenses and morbidity associated with surgery.

A few clinical and technical factors have been reported to predict which patients with ADH at image-guided biopsy are more likely to have an upgrade to malignancy at surgery; these include patient age, lesion size, number of biopsy samples collected, caliber of the needle used for image-guided biopsy, and personal and family history of breast cancer [11-14]. Nevertheless, these factors are not yet enough to change the current recommendation of surgical excision as the current standard of care after $\mathrm{ADH}$ is diagnosed at image-guided biopsy $[7,15]$. As to imaging features, initial studies involving magnetic resonance imaging (MRI) have shown that no specific imaging feature was able to predict an upgrade for high-risk lesions when detected with MRI [16], and the subsequent upgrade rate for these lesions was between 14 and 38\% at surgical excision [17-19].

In this context, artificial intelligence approaches to imaging may present a breakthrough. Several investigators have used various machine learning and computational approaches to predict subsequent upgrades of $\mathrm{ADH}$, using mammographic data, clinical data, and data acquired from biopsy samples $[10,11]$. However, to date, no study has applied artificial intelligence to MRI to predict such upgrades. Thus, the aim of the present study was to determine if radiomics analysis coupled with machine learning using MRI data can distinguish which image-guided biopsied lesions with a histological diagnosis of ADH will be upgraded to DCIS or invasive ductal carcinoma (IDC) at surgery. A secondary aim was to determine if qualitatively and semi-quantitatively assessed imaging features, clinical factors, and image-guided biopsy technical factors are associated with upgrade status at surgery.

\section{Materials and methods}

\section{Study population}

This was an institutional review board-approved and Health Insurance Portability and Accountability Act-compliant retrospective study for which the need for written informed consent was waived. This study included patients who underwent state-of-the-art multiparametric MRI with dynamic contrast-enhanced imaging and T2-weighted imaging using a dedicated breast coil, either at our institution or elsewhere, prior to image-guided biopsy (MRI-, ultrasound-, or stereotactic-guided biopsy). We included patients with a suspicious finding on MRI (mass or non-mass enhancement of any size), with or without an ultrasound or mammographic correlate, which on subsequent pathology yielded a diagnosis of ADH (alone or associated with other highrisk lesions) and subsequent surgical excision confirming a benign finding or an upgrade to malignancy. We excluded patients if they underwent a mastectomy for an ipsilateral cancer for which the pathological report was unclear as to which pathological finding was related to the biopsy that yielded ADH.

For all patients, clinical data (patient age, history of breast cancer, presence of ipsilateral or contralateral breast cancer), technical data (caliber of needle used, number of sampled specimens), and pathologic results from the subsequent surgery were collected.

\section{Breast MRI}

Breast MRI examinations were performed on either a $1.5 \mathrm{~T}$ or a $3 \mathrm{~T}$ scanner using an 8-channel or 16-channel dedicated surface breast coil. Patients underwent state-of-the-art breast multiparametric MRI protocol in agreement with international guidelines [20, 21].

\section{Imaging analysis}

Two fellowship-trained breast radiologists (RLG and KV) with 5 and 2 years of experience interpreted the MR images independently, blinded to patient family and personal history, biopsy results, and pathologic results from the subsequent surgery. Cases in which there was a disagreement between the two readers were re-reviewed by a third reader (CRS) with 6 years of experience to generate a consensus assessment.

On post-contrast-enhanced T1-weighted images, lesion depth (anterior, middle, or posterior depth) was recorded for each lesion as this has been shown to be correlated with malignancy [22]. Morphological features were also assessed according to the Breast Imaging-Reporting and Data System (BI-RADS) lexicon (lesion shape, margin, and internal enhancement characteristics for mass lesions, and distribution and type of enhancement for non-mass enhancements) [23], and readers assigned a BI-RADS classification. Lesion size was measured as the single largest diameter. On T2-weighted and high b-value diffusionweighted images, signal intensity (hypo-, iso-, hyperintense) 
and morphology were recorded. Background parenchymal enhancement and fibroglandular tissue were also assessed using maximum intensity projection images and non-fat saturated T1-weighted images, respectively. Time-intensity kinetic curve analysis (signal enhancement in relation to time after contrast injection) was performed using the ROI Enhancement plugin in the OsiriX software [24] by R1. The kinetic curve pattern was described as washout, plateau, or persistent.

\section{Radiomics analysis}

One hundred and one radiomic features were calculated for each patient with CERR software [25], publicly available via GitHub, using MATLAB 2017b (The MathWorks Inc., Natick, MA) and an in-house script was written for batch processing of patient images [14]. The features calculated can be defined as belonging to six classes, based on firstorder statistics (22), gray-level co-occurrence matrix (26), run-length matrix (16), size zone matrix (16), neighborhood gray-level dependence matrix (16), and neighborhood gray-tone difference matrix (5), respectively. CERR has recently been shown to conform to the Image Biomarker Standardization Initiative (IBSI) guidelines [26]. Radiomic features were calculated from pre- and post-contrast administration. Delta radiomics, defined as the percentage change in radiomic features between the two timepoints, was also determined. Images were decimated to $32 \mathrm{~Gy}$ levels prior to feature calculation.

\section{Histopathology}

Histopathological results from surgical specimens were used as the reference standard. The criteria used to distinguish $\mathrm{ADH}$ from DCIS included the presence of at least one of the following two quantitative features according to the World Health Organization classification of breast tumors size limited to $2 \mathrm{~mm}$ or smaller and/or involvement of no more than two membrane bound spaces [8].

\section{Statistical analysis and predictive model building}

Univariate analysis using the Chi-square test or Fisher's exact test was performed to assess associations between imaging features and upgrade status. Differences in lesion size and number of specimens between the two groups were assessed using the Mann-Whitney test. $P$-values $<0.05$ were considered significant. To determine inter-reader agreement for qualitatively and semi-quantitatively assessed imaging parameters, Cohen's Kappa (к) was estimated. Statistical analysis for the above-mentioned purposes was conducted using SAS version 9.4 software (SAS Institute, Cary, NC, USA).
For radiomic features, data were summarized utilizing medians and inter-interquartile range. Associations between radiomic features and upgrade status were explored using the Mann-Whitney test, with $p$-values $<0.05$ regarded as significant. Following univariate analysis, predictive models from radiomic features were created. Correlation analysis was initially employed to remove redundant parameters from advancement to model development, to reduce the possibility of overfitting. If a highly positive ( $>0.9$ ) or highly negative $(<-0.9)$ correlation was noted, the parameter with the lowest area under the receiver operating curve (AUROC) was removed. After parameter selection, undersampling techniques were employed, due to the large imbalance between the majority (no-upgrade) and minority (upgrade) class sizes, to reduce the possibility of any algorithm incorrectly classifying all lesions as belonging to the majority class. Random undersampling at 50\% minority class size was utilized for both classes and this process was repeated 1000 times for generalizability. Five-fold cross validation was utilized in place of dedicated train/test datasets and a gaussian support vector machine algorithm was employed. As the current recommendation for lesions diagnosed as $\mathrm{ADH}$ at image-guided biopsy is surgical excision, a 50\% increased penalty for misclassifying a non-upgraded lesion was utilized. This will have the effect of increasing specificity at the expense of sensitivity to upgraded lesions.

\section{Results}

\section{Patient population and breast lesion characteristics}

This study included 127 patients (average age $51.2 \pm 10.2$; range 27-78) with 139 lesions, of which 28/139 lesions were upgraded to DCIS or IDC on surgery while 111/139 lesions were not upgraded (Fig. 1). The average lesion size was $15.14 \pm 13.23 \mathrm{~mm}$ (range $3-70 \mathrm{~mm}$ ). The majority of lesions (125/139) was assessed with MRI at our institution, while a minority (14/139) was assessed with MRI from an outside institution.

\section{Radiomics analysis to predict upgrade status}

At univariate analysis, 11 radiomic features were found to be significantly different between the two groups (no-upgrade vs upgrade) when utilizing pre-contrast data, 10 radiomic features were significantly different when utilizing percentage change in radiomic features between pre- and post-contrast data, and no radiomic feature was significantly different between the two groups when utilizing post-contrast data. Following correlation analysis, four radiomics features were advanced to model development for both the pre-contrast and delta radiomics datasets. These included 1 first-order 
Fig. 1 Contrast-enhanced T1-weighted fat-suppressed subtraction maximum intensity projection images in the axial (a, d) sagittal (b, e) and coronal $(\mathbf{c}, \mathbf{f})$ planes with (top row) and without segmentation (bottom row), showing a $1.3 \mathrm{~cm}$ focal non-mass enhancement in the left upper outer quadrant. MRIguided biopsy yielded atypical ductal hyperplasia (ADH), $\mathrm{ADH}$ diagnosis was confirmed on surgical specimen

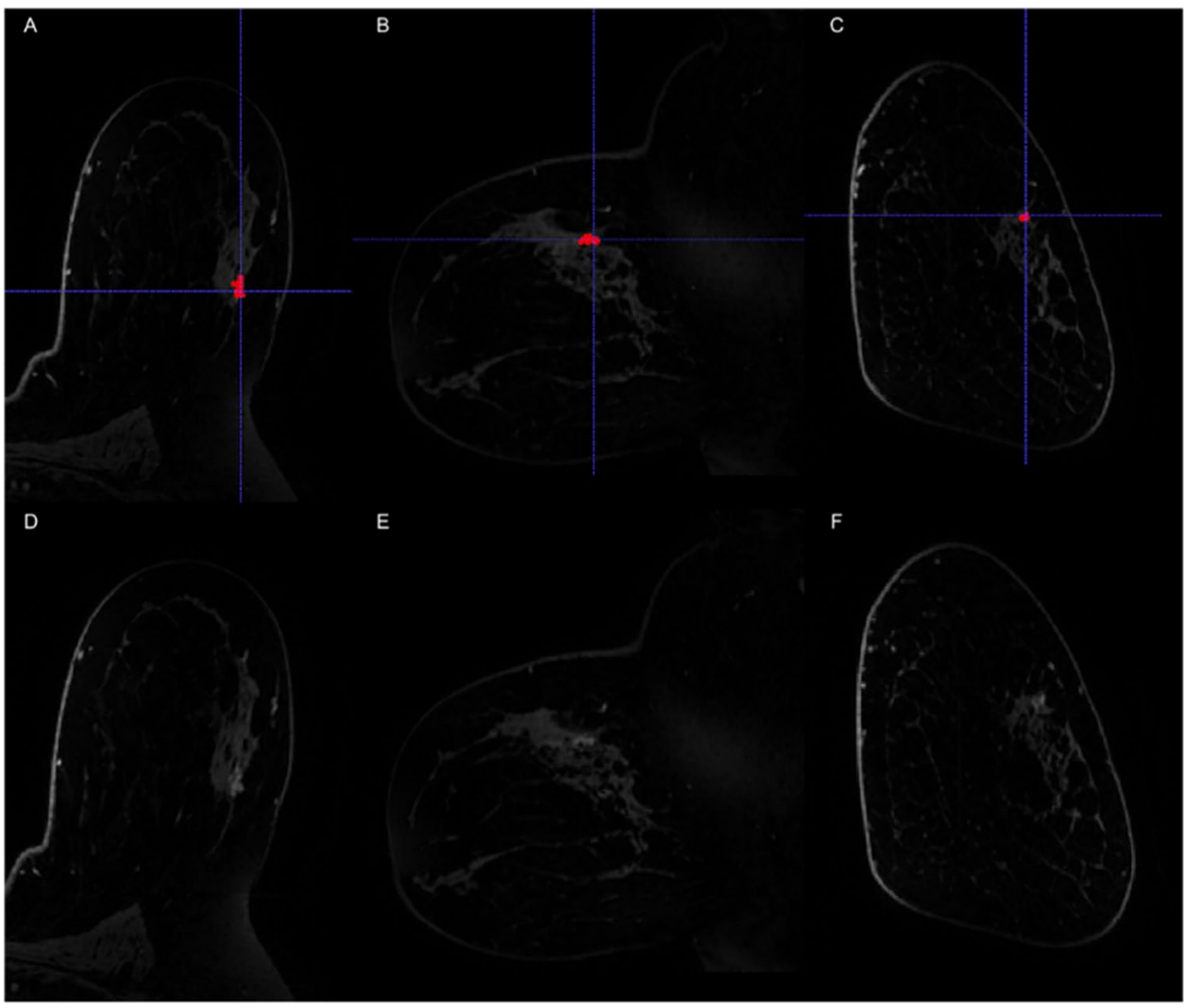

feature (Minimum), 1 run-length matrix feature (run-length variance) and 2 neighborhood gray-tone difference matrix features (high dependence high gray-level emphasis and Busyness), findings are summarized in Tables 1 and 2 .

Table 3 details the diagnostic performance of the two models. For both the pre-contrast and delta radiomics models, a specificity of around $80 \%$ was obtained but at the expense of poor sensitivity (15.3-22.8\%). As can be seen, there was a slight improvement in diagnostic accuracy from $53.6 \%$ for the pre-contrast radiomics model to $60.7 \%$ for the delta radiomics model.

\section{Association of qualitatively and semi-quantitatively assessed imaging parameters with upgrade status}

Table 4 shows the inter-reader agreement between $\mathrm{R} 1$ and R2. For BI-RADS assessment, while there was agreement in $128 / 139$ cases, the $\kappa$ value of 0.24 showed low agreement, probably due to the low number or BI-RADS category 3 lesions as compared to category 4 lesions. Agreement was moderate for background parenchymal enhancement, T2 and DWI signal intensity, and shape. Agreement was good for fibroglandular tissue, apparent diffusion coefficient signal intensity, and distribution of non-mass enhancement. There was very good agreement for lesion depth within the breast.

Table 5 shows the results from univariate analysis according to independent assessments by the two radiologists.
Table 6 shows the results from univariate analysis according to consensus assessment. In consensus reading, no significant associations were found between any radiologistassessed lesion parameter and upgrade status.

Time-intensity kinetic curve analysis was performed in 135/139 lesions; four lesions were not analyzed due to motion-related artifacts. Progressive contrast enhancement was present in 54 lesions, plateau kinetics was present in 63 lesions, and washout was seen in 18 lesions. There was no association between kinetics and upgrade rate $(p=0.2)$.

\section{Association between clinical and image-guided biopsy technical parameters}

Table 7 shows the results from univariate analysis of clinical and image-guided biopsy technical parameters with upgrade status. The average number of biopsy samples was $8 \pm 2.7$, and there was a significant correlation between the number of specimens sampled during biopsy and upgrade status $(p=0.003)$. All other parameters were insignificant between the two groups. 
Table 1 Summary of significant Mann-Whitney U tests for radiomic features created from pre-contrast images

\begin{tabular}{|c|c|c|c|}
\hline Radiomic feature & $\begin{array}{l}\text { No-upgrade } \\
\text { Median (IQR) }\end{array}$ & $\begin{array}{l}\text { Upgrade } \\
\text { Median (IQR) }\end{array}$ & $p$-value \\
\hline Skewness (FO) & $\begin{array}{l}-0.322 \\
(-0.629 \text { to } 0.186)\end{array}$ & $\begin{array}{l}-0.580 \\
(-1.013 \text { to }-0.342)\end{array}$ & 0.011 \\
\hline Joint average (GLCM) & $\begin{array}{l}18.7 \\
\text { (16.2 to } 20.3)\end{array}$ & $\begin{array}{l}19.9 \\
(17.2 \text { to } 22.0)\end{array}$ & 0.025 \\
\hline Sum average (GLCM) & $\begin{array}{l}37.3 \\
\text { (32.3 to } 40.7 \text { ) }\end{array}$ & $\begin{array}{l}39.8 \\
(34.5 \text { to } 44.0)\end{array}$ & 0.025 \\
\hline Auto correlation (GLCM) & $\begin{array}{l}362 \\
(286 \text { to } 434)\end{array}$ & $\begin{array}{l}412 \\
(313 \text { to } 495)\end{array}$ & 0.029 \\
\hline hglre (RLM) & $\begin{array}{l}358 \\
(288 \text { to } 422)\end{array}$ & $\begin{array}{l}397 \\
(313 \text { to } 485)\end{array}$ & 0.036 \\
\hline lrhgle (RLM) & $\begin{array}{l}462 \\
\text { ( } 377 \text { to } 581 \text { ) }\end{array}$ & $\begin{array}{l}567 \\
(427 \text { to } 659)\end{array}$ & 0.018 \\
\hline srhgle (RLM) & $\begin{array}{l}333 \\
\text { (266 to } 392)\end{array}$ & $\begin{array}{l}360 \\
(294 \text { to } 437)\end{array}$ & 0.049 \\
\hline hglze (SZM) & $\begin{array}{l}347 \\
(284 \text { to } 414)\end{array}$ & $\begin{array}{l}389 \\
(305 \text { to } 469)\end{array}$ & 0.042 \\
\hline lzhgle (SZM) & $\begin{array}{l}1027 \\
\text { (726 to } 1462)\end{array}$ & $\begin{array}{l}1281 \\
\text { (937 to } 1965)\end{array}$ & 0.040 \\
\hline hgce (NGLDM) & $\begin{array}{l}363 \\
(288 \text { to } 427)\end{array}$ & $\begin{array}{l}399 \\
\text { (314 to } 490)\end{array}$ & 0.038 \\
\hline hdhge (NGLDM) & $\begin{array}{l}1266 \\
\text { (936 to } 1778)\end{array}$ & $\begin{array}{l}1542 \\
\text { (1209 to 2280) }\end{array}$ & 0.021 \\
\hline
\end{tabular}

Median values with associated interquartile range (IQR) are reported as non-parametric tests were performed. Features selected for advancement to model development are italicized

$F O$ first-order, GLCM gray-level co-occurrence matrix, RLM run-length matrix, SZM size zone matrix, $N G L D M$ neighborhood gray-level dependence matrix, hglre high gray-level run emphasis, lrhgle long-run high gray-level emphasis, srhgle short-run high gray-level emphasis, hglze high gray-level zone emphasis; lzhgle large zone high gray-level emphasis, hgce high gray-level count emphasis, hdhge high dependence high gray-level emphasis

\section{Discussion}

We undertook this study with the primary hypothesis that radiomics analysis coupled with machine learning using MRI data can distinguish which image-guided biopsied lesions with a histological diagnosis of ADH will be upgraded to a malignant lesion at surgery, but our results showed otherwise. A secondary aim was to determine if conventional qualitatively and semi-quantitatively assessed imaging features, clinical factors, and image-guided biopsy technical factors are associated with upgrade status at surgery. The only significant result from this analysis is between the number of specimens sampled during biopsy procedure and upgrade status at surgery.

In our study, we included MRI scans performed prior to image-guided biopsy showing suspicious enhancement. The upgrade rate at a later surgical excision was $25.5 \%$, which is comparable to that of mammographically detected ADH and unacceptably high to warrant surveillance but also not high enough to justify a costly and invasive surgical procedure for all patients with biopsy-proven ADH. The results published so far on this topic are variable, and to date, no consensus exists regarding the selection of biopsy-proven ADH lesions that may safely undergo observation. A study by Tsuchiya et al. [6] reported that patients with biopsy-proven ADH without suspicious enhancement on breast MRI may be followed up rather than undergo surgical excision, given the high negative predictive value of MRI. This study included only 17 patients ( $9 / 17$ patients were upgraded to malignancy on surgery) and only looked at post-biopsy MRIs in which it may be difficult to differentiate post-biopsy changes from suspicious persistent enhancement. Another study by Linda et al. [25] included 79 patients with ADH diagnosed on core needle biopsy. The authors reported that cases showing mild or no enhancement on MRI can be followed rather than having surgery. In their study, 8/24 lesions that showed enhancement on MRI were associated with an upgrade on surgical biopsy, whereas only one (1.8\%, a low-grade DCIS) of 55 lesions classified as non-suspicious was confirmed to be malignant. Another study by Pediconi et al. [26] assessing 32 high-risk lesions (including ADH) reported that cases of non-suspicious enhancement or no enhancement at breast MRI may undergo follow-up rather than surgery. Although these studies suggest that ADH could be followed with 
Table 2 Summary of significant Mann-Whitney U tests for percentage change in radiomics features between pre- and post-contrast images

\begin{tabular}{|c|c|c|c|}
\hline Radiomic feature & $\begin{array}{l}\text { No-upgrade } \\
\text { Median (IQR) }\end{array}$ & $\begin{array}{l}\text { Upgrade } \\
\text { Median (IQR) }\end{array}$ & $p$-value \\
\hline Minimum $(F O)$ & $\begin{array}{l}122 \\
\text { (80 to } 228)\end{array}$ & $\begin{array}{l}184 \\
\text { (111 to } 333)\end{array}$ & 0.041 \\
\hline Sum average (GLCM) & $\begin{array}{l}-16.7 \\
(-23.9 \text { to }-1.1)\end{array}$ & $\begin{array}{l}-21.8 \\
(-35.4 \text { to }-8.3)\end{array}$ & 0.047 \\
\hline $\begin{array}{l}\text { Auto correlation } \\
\text { (GLCM) }\end{array}$ & $\begin{array}{l}-26.4 \\
(-38.7 \text { to } 0.5)\end{array}$ & $\begin{array}{l}-32.3 \\
(-54.3 \text { to }-12.8)\end{array}$ & 0.044 \\
\hline lrhgle (RLM) & $\begin{array}{l}-35.7 \\
(-47.9 \text { to }-13.6)\end{array}$ & $\begin{array}{l}-44.8 \\
(-63.9 \text { to }-22.6)\end{array}$ & 0.026 \\
\hline$r l v(R L M)$ & $\begin{array}{l}-30.0 \\
(-48.1 \text { to }-5.8)\end{array}$ & $\begin{array}{l}-39.2 \\
(-58.7 \text { to }-24.0)\end{array}$ & 0.045 \\
\hline lzhgle (SZM) & $\begin{array}{l}-46.7 \\
(-60.6 \text { to }-20.0)\end{array}$ & $\begin{array}{l}-63.8 \\
(-73.0 \text { to }-39.7)\end{array}$ & 0.008 \\
\hline hde (NGLDM) & $\begin{array}{l}-21.1 \\
(-36.8 \text { to }-3.8)\end{array}$ & $\begin{array}{l}-30.4 \\
(-44.4 \text { to }-14.4)\end{array}$ & 0.047 \\
\hline hgce (NGLDM) & $\begin{array}{l}-31.4 \\
(-41.6 \text { to }-4.7)\end{array}$ & $\begin{array}{l}-38.0 \\
(-56.8 \text { to }-14.6)\end{array}$ & 0.047 \\
\hline hdhge (NGLDM) & $\begin{array}{l}-42.4 \\
(-60.6 \text { to }-20.0)\end{array}$ & $\begin{array}{l}-61.8 \\
(-72.9 \text { to }-30.5)\end{array}$ & 0.006 \\
\hline Busyness (NGTDM) & $\begin{array}{l}108 \\
(47 \text { to } 176)\end{array}$ & $\begin{array}{l}160 \\
\text { (63 to 206) }\end{array}$ & 0.047 \\
\hline
\end{tabular}

Median values with associated interquartile range (IQR) are reported as non-parametric tests were performed. Features selected for advancement to model development are italicized

$F O$ first-order, GLCM gray-level co-occurrence matrix, $R L M$ runlength matrix, $S Z M$ size zone matrix, $N G L D M$ neighborhood graylevel dependence matrix, $N G T D M$ neighborhood gray-tone difference matrix, lrhgle long-run high gray-level emphasis, rlv run-length variance, lzhgle large zone high gray-level emphasis, hde high dependence emphasis, hgce high gray-level count emphasis, hdhge high dependence high gray-level emphasis

imaging rather than surgically removed in case of no or little contrast enhancement on MRI, another more recent study, also by Linda et al. [27], with a larger sample of 169 highrisk lesions in 166 patients yielded contradicting results: the overall sensitivity, specificity, and positive and negative predictive values of MRI to determine upgrade to malignancy were $72.7 \%, 74.8 \%, 30.2 \%$, and $94.8 \%$, respectively. The authors concluded that a negative MRI study warrants follow-up instead of surgery only for lesions with low likelihood of malignancy such as papilloma and radial scar, but it does not help in cases of lobular neoplasia and ADH, and all these latter lesions should be excised.

In our study, MRI-based radiomics analysis coupled with machine learning was not able to accurately predict which biopsy-proven ADH lesions would be upgraded to malignancy at surgery. Although a specificity of around $80 \%$ was obtained, this was done at the expense of poor sensitivity. As can be seen, there was a slight improvement in diagnostic accuracy from 53.6 to $60.7 \%$ when the radiomics model was based on percentage change in radiomic features between pre- and post-contrast data rather than using only pre-contrast data. Our results involving radiomics analysis are in contrast to a similar study by Ha et al. [10] that included 149 patients who underwent mammography, wherein the convolutional neural network yielded an area under the curve (AUC) of 0.86 , sensitivity of $84.6 \%$, specificity of $88.2 \%$,

Table 4 Agreement between reader 1 and reader 2. A $\kappa<0.20$ was indicative of poor agreement, $\kappa$ of $0.20-0.40$ indicated fair agreement, $\kappa$ of $0.41-0.60$ indicated moderate agreement, $\kappa$ of $0.61-0.80$ indicated good agreement, and $\kappa$ of $0.81-1.00$ indicated very good agreement

\begin{tabular}{lll}
\hline Comparison & $\kappa$ & $p$-value \\
\hline BPE & 0.573962 & 0 \\
FGT & 0.736386 & 0 \\
Depth & 0.836347 & 0 \\
T2 & 0.427319 & $3.26 \mathrm{E}-10$ \\
DWI & 0.534687 & $6.79 \mathrm{E}-11$ \\
ADC & 0.620233 & $6.23 \mathrm{E}-10$ \\
BI-RADS & 0.247909 & $9.22 \mathrm{E}-06$ \\
Enhancement type & 0.888129 & 0 \\
Shape & 0.569255 & $1.27 \mathrm{E}-11$ \\
Margins & 0.581662 & $3.44 \mathrm{E}-10$ \\
Enhancement (mass) & 0.388235 & $2.92 \mathrm{E}-05$ \\
Distribution & 0.698065 & 0 \\
Enhancement (non-mass) & 0.47231 & $6.93 \mathrm{E}-08$ \\
\hline
\end{tabular}

$A D C$ apparent diffusion coefficient, $B I-R A D S$ breast imaging-reporting \& data system, $B P E$ background parenchymal enhancement, $D W I$ diffusion-weighted imaging, FGT fibroglandular tissue

Table 3 Summary of predictive models based on pre-contrast images and percentage change in radiomics features between pre- and post-contrast images

\begin{tabular}{lllllll}
\hline & AUROC & Sensitivity $(\%)$ & Specificity $(\%)$ & PPV $(\%)$ & NPV (\%) & Accuracy (\%) \\
\hline Pre-contrast & 0.514 & 15.3 & 79.2 & 34.8 & 48.7 & 53.6 \\
& $(0.299-0.728)$ & $(1.8-42.8)$ & $(49.2-95.3)$ & $(11.6-77.3)$ & $(39.3-56.5)$ & $(27.5-66.1)$ \\
Percentage change & 0.540 & 22.8 & 86.0 & 57.5 & 53.0 & 60.7 \\
& $(0.329-0.752)$ & $(4.7-50.8)$ & $(57.2-98.2)$ & $(22.7-88.4)$ & $(43.5-60.7)$ & $(33.9-72.5)$ \\
\hline
\end{tabular}

Models were created using gaussian support vector machines (SVMs) and are presented with confidence intervals

$A U R O C$ area under the receiver operating curve, $N P V$ negative predictive value, $P P V$ positive predictive value 
Table 5 Univariate analysis according to independent radiologist assessment

\begin{tabular}{|c|c|c|c|c|c|c|c|c|}
\hline \multirow[t]{2}{*}{ Imaging feature } & \multicolumn{3}{|l|}{ Reader 1} & \multirow[t]{2}{*}{$p$-value } & \multicolumn{3}{|l|}{ Reader 2} & \multirow[t]{2}{*}{$p$-value } \\
\hline & Overall & No-upgrade & Upgrade & & Overall & No-upgrade & Upgrade & \\
\hline $\mathrm{BPE}$ & & & & 0.11 & & & & 0.9 \\
\hline Minimal & $33(24)$ & $27(24)$ & $6(21)$ & & $24(17)$ & $20(18)$ & $4(14)$ & \\
\hline Mild & $46(33)$ & $39(35)$ & $7(25)$ & & $41(29)$ & $34(31)$ & $7(25)$ & \\
\hline Moderate & $50(36)$ & $35(32)$ & $15(54)$ & & $55(40)$ & $42(38)$ & $13(46)$ & \\
\hline Marked & $10(7.2)$ & $10(9)$ & $0(0)$ & & $19(14)$ & $15(14)$ & $4(14)$ & \\
\hline FGT & & & & 0.6 & & & & 0.8 \\
\hline Almost entirely fat & $2(1.4)$ & $1(0.9)$ & $1(3.6)$ & & 1 & $1(0.9)$ & $0(0)$ & \\
\hline Scattered FGT & $35(25)$ & $28(25)$ & $7(25)$ & & $37(27)$ & $29(26)$ & $8(29)$ & \\
\hline Heterogeneous FGT & $91(65)$ & $72(65)$ & $19(68)$ & & $73(53)$ & $57(51)$ & $16(57)$ & \\
\hline Extreme FGT & $11(7.9)$ & $10(9)$ & $1(3.6)$ & & $28(20)$ & $24(22)$ & $4(14)$ & \\
\hline Depth & & & & $>0.9$ & & & & 0.9 \\
\hline Anterior & $35(25)$ & $28(25)$ & $7(25)$ & & $36(26)$ & $28(25)$ & $8(29)$ & \\
\hline Middle & $74(53)$ & $59(53)$ & $15(54)$ & & $70(50)$ & $57(51)$ & $13(46)$ & \\
\hline Posterior & $30(22)$ & $24(22)$ & $6(21)$ & & $33(24)$ & $26(23)$ & $7(25)$ & \\
\hline $\mathrm{T} 2$ signal intensity & & & & 0.9 & & & & 0.8 \\
\hline Hypointense & $2(1.4)$ & $2(1.8)$ & $0(0)$ & & $17(12)$ & $13(12)$ & $4(14)$ & \\
\hline Isointense & $99(71)$ & $78(70)$ & $21(75)$ & & $85(61)$ & $67(60)$ & $18(64)$ & \\
\hline Hyperintense & $38(27)$ & $31(28)$ & $7(25)$ & & $37(27)$ & $31(28)$ & $6(21)$ & \\
\hline DWI signal (75 lesions) & & & & 0.7 & & & & 0.5 \\
\hline Homogeneous & $29(39)$ & $24(41)$ & $5(29)$ & & $28(37)$ & $24(41)$ & $4(24)$ & \\
\hline Heterogeneous & $6(8)$ & $4(6.9)$ & $2(12)$ & & $16(21)$ & $12(21)$ & $4(24)$ & \\
\hline $\operatorname{Rim}$ & $1(1.3)$ & $1(1.7)$ & $0(0)$ & & $1(1.3)$ & $1(1.7)$ & $0(0)$ & \\
\hline No correlate & $39(52)$ & $29(50)$ & $10(59)$ & & $30(40)$ & $21(36)$ & $9(53)$ & \\
\hline ADC signal (61 lesions) & & & & 0.4 & & & & $>0.9$ \\
\hline Hyperintense & $4(6.6)$ & $3(6.4)$ & $1(7.1)$ & & $4(6.6)$ & $3(6.4)$ & $1(7.1)$ & \\
\hline Hypointense & $7(11)$ & $4(8.5)$ & $3(21)$ & & $10(16)$ & $8(17)$ & $2(14)$ & \\
\hline No correlate & $50(82)$ & $40(85)$ & $10(71)$ & & 47 (77) & $36(77)$ & $11(79)$ & \\
\hline BI-RADS & & & & 0.7 & & & & $>0.9$ \\
\hline 3 & $13(9.4)$ & $10(9)$ & $3(11)$ & & $2(1.4)$ & $2(1.8)$ & $0(0)$ & \\
\hline 4 & $126(91)$ & $101(91)$ & $25(89)$ & & 137 (99) & $109(98)$ & $28(100)$ & \\
\hline Enhancement type & & & & 0.6 & & & & 0.6 \\
\hline Mass like & $70(50)$ & $58(52)$ & $12(43)$ & & $66(47)$ & $55(50)$ & $11(39)$ & \\
\hline Non-mass like & $67(48)$ & $51(46)$ & $16(57)$ & & $71(51)$ & $54(49)$ & $17(61)$ & \\
\hline Mixed & $2(1.4)$ & $2(1.8)$ & $0(0)$ & & $2(1.4)$ & $2(1.8)$ & $0(0)$ & \\
\hline Shape (mass) & & & & 0.3 & & & & 0.2 \\
\hline Oval & $19(26)$ & $18(30)$ & $1(8.3)$ & & $13(18)$ & $13(21)$ & $0(0)$ & \\
\hline Round & $16(22)$ & $12(20)$ & $4(33)$ & & $19(26)$ & $15(24)$ & $4(33)$ & \\
\hline Irregular & $38(52)$ & $31(51)$ & $7(58)$ & & $42(57)$ & $34(55)$ & $8(67)$ & \\
\hline Margins (mass) & & & & 0.8 & & & & 0.5 \\
\hline Circumscribed & $30(41)$ & $25(41)$ & $5(42)$ & & $36(49)$ & $32(52)$ & $4(3)$ & \\
\hline Irregular & $34(47)$ & $29(48)$ & $5(42)$ & & $32(43)$ & $25(40)$ & $7(58)$ & \\
\hline Spiculated & $9(12)$ & $7(11)$ & $2(17)$ & & $6(8.1)$ & $5(8.1)$ & $1(8.3)$ & \\
\hline Enhancement (mass) & & & & 0.3 & & & & 0.4 \\
\hline Homogeneous & $28(38)$ & $25(40)$ & $3(25)$ & & $37(49)$ & $33(52)$ & $4(33)$ & \\
\hline Heterogeneous & $35(47)$ & $29(47)$ & $6(50)$ & & $38(51)$ & $30(48)$ & $8(67)$ & \\
\hline Rim enhancement & $8(11)$ & $5(8.1)$ & $3(35)$ & & $0(0)$ & $0(0)$ & $0(0)$ & \\
\hline Dark internal septations & $3(4.1)$ & $3(4.8)$ & $0(0)$ & & $0(0)$ & $0(0)$ & $0(0)$ & \\
\hline Distribution (non-mass) & & & & 0.2 & & & & 0.3 \\
\hline
\end{tabular}


Table 5 (continued)

\begin{tabular}{|c|c|c|c|c|c|c|c|c|}
\hline \multirow[t]{2}{*}{ Imaging feature } & \multicolumn{3}{|c|}{ Reader 1} & \multirow[t]{2}{*}{$p$-value } & \multicolumn{3}{|c|}{ Reader 2} & \multirow[t]{2}{*}{$p$-value } \\
\hline & Overall & No-upgrade & Upgrade & & Overall & No-upgrade & Upgrade & \\
\hline Focal & $23(33)$ & $20(37)$ & $3(19)$ & & $26(35)$ & $22(39)$ & $4(24)$ & \\
\hline Linear & $27(39)$ & $22(41)$ & $5(31)$ & & $26(35)$ & $21(37)$ & $5(29)$ & \\
\hline Segmental & $18(26)$ & $11(20)$ & $7(44)$ & & $19(26)$ & $12(21)$ & $7(41)$ & \\
\hline Regional & $4(2.9)$ & $1(1.9)$ & $1(6.2)$ & & $3(4.1)$ & $2(3.5)$ & $1(5.9)$ & \\
\hline Multiple regions & $0(0)$ & $0(0)$ & $0(0)$ & & $0(0)$ & $0(0)$ & $0(0)$ & \\
\hline Diffuse & $0(0)$ & $0(0)$ & $0(0)$ & & $0(0)$ & $0(0)$ & $0(0)$ & \\
\hline Enhancement (non-mass) & & & & 0.2 & & & & 0.5 \\
\hline Homogeneous & $15(21)$ & $9(17)$ & $6(38)$ & & $16(22)$ & $12(21)$ & $4(24)$ & \\
\hline Heterogeneous & $35(50)$ & $29(54)$ & $6(38)$ & & $41(55)$ & $30(53)$ & $11(65)$ & \\
\hline Clumped & $20(29)$ & $16(30)$ & $4(25)$ & & $17(23)$ & $15(26)$ & $2(12)$ & \\
\hline Clustered rings & $0(0)$ & $0(0)$ & $0(0)$ & & $0(0)$ & $0(0)$ & $0(0)$ & \\
\hline
\end{tabular}

$A D C$ apparent diffusion coefficient, $B I-R A D S$ breast imaging-reporting \& data system, $B P E$ background parenchymal enhancement, $D W I$ diffusion-weighted imaging, FGT fibroglandular tissue

and a diagnostic accuracy of $86.7 \%$. Our results involving radiomics analysis also contradict a study by Cheeney et al. [28] that included 23 high-risk lesions which demonstrated that lesion size and ADC values showed promise for predicting which MRI-detected high-risk lesions will be upgraded to malignancy at surgical excision; in our study, the size of target lesions and radiomic features from diffusion-weighted imaging did not add any value to the machine learning model. Harrington et al. [11] developed machine learning models to predict ADH upgrade in 128 biopsy specimens and concluded that the most important predictors for upgrade status were patient age, size of lesion, number of biopsies, and personal and family history of cancer; however, they did not evaluate imaging features for inclusion into their models. Constant improvements in software and hardware may further improve the accuracy for characterization of high-risk lesions on MRI in the future.

We also found no significant associations between any qualitatively or semi-qualitatively assessed lesion feature on MRI, whether from independent or consensus imaging assessment, and upgrade status ( $p$-values ranging from 0.11 to $>0.9)$. In terms of DCE-MRI features in particular to predict high-risk lesion upgrade risk, our findings agree with the literature which has thus far found morphology and kinetic characteristics to be unpredictive of ADH upgrade to DCIS/IDC at surgery [16, 18, 29, 30].

The lack of significant results involving radiomics or conventional imaging features in our study could be related to the fact that the distinction between ADH and DCIS relies solely on the quantity of atypia present on pathologic specimens (size limited to $2 \mathrm{~mm}$ or smaller and involvement of no more than two membrane bound spaces), and thus, it is understandable that imaging features could be similar when comparing two entities that are qualitatively identical. The diagnosis of ADH remains a diagnostic challenge for pathologists, as significant interobserver variability has been reported for both general pathology and breast pathology specialists [31].

Apart from radiomics and conventional imaging-based features, we found that the number of tumor specimens obtained at image-guided biopsy was significantly associated with the upgrade rate. Lesions that were upgraded at surgery had fewer specimens biopsied compared to lesions that were confirmed as $\mathrm{ADH}$ at surgery. This is in line with a previous study by Nguyen et al. [32] that showed that incomplete removal of calcifications on stereotactic biopsy $(<95 \%$ of the biopsy target) is associated with a higher upgrade rate at surgery. A large retrospective study by Deshaies et al. [12] that included 422 biopsy-confirmed ADH lesions found several independent predictors of an upgrade at surgery, including mammographic lesions, other microcalcifications, and use of a $14 \mathrm{G}$ needle. History of ipsilateral or contralateral cancer as well as presence of ipsilateral or contralateral synchronous breast cancer did not affect upgrade rate.

This study has several limitations. The patient cohort used in this study is highly unbalanced (111 patients in the no-upgrade group vs 28 patients in the upgrade group) and while this does not affect univariate analysis using the Chi-square test or the Mann-Whitney test, it may have affected the performance of the predictive models created with machine learning. Future work similar to this may use data balancing techniques such as SMOTE [33] or ADASYN [34] to create synthetic data with the aim of finding more subtle patterns, or more preferably a higher number of patients with the intent to keep datasets balanced. These were, however, not done in this study 
Table 6 Univariate analysis according to consensus radiologist assessment

\begin{tabular}{ll}
\hline Imaging feature & Upgrade status \\
\cline { 2 - 3 } & Overall No-value \\
\end{tabular}

\begin{tabular}{lllll}
\hline BPE & & & & 0.11 \\
Minimal & $21(15)$ & $17(15)$ & $4(14)$ & \\
Mild & $56(40)$ & $47(42)$ & $9(32)$ & \\
Moderate & $51(37)$ & $36(32)$ & $15(54)$ & \\
Marked & $11(7.9)$ & $11(9.9)$ & $0(0)$ &
\end{tabular}

FGT

$\begin{array}{lllll}\text { Almost entirely fat } & 1(0.7) & 1(0.9) & 0(0) & 0.7 \\ \text { Scattered FGT } & 37(27) & 28(25) & 9(32) & \\ \text { Heterogeneous FGT } & 89(64) & 71(64) & 18(64) & \\ \text { Extreme FGT } & 12(8.6) & 11(9.9) & 1(3.6) & \\ \text { Depth } & & & & >0.9 \\ \text { Anterior } & 36(26) & 28(25) & 8(29) & \\ \text { Middle } & 72(52) & 58(52) & 14(50) & \\ \text { Posterior } & 31(22) & 25(23) & 6(21) & \end{array}$

T2 signal intensity

Hypointense
Isointense

Hyperintense

DWI signal (75 lesions)

Homogeneous
Heterogeneous
Rim
No correlate
ADC signal (61 lesions)
Hyperintense
Hypointense
No correlate
BI-RADS

\section{3}

4

Enhancement type

$\begin{array}{llll}\text { Mass like } & 71(51) & 59(53) & 12(43) \\ \text { Non-mass like } & 66(47) & 50(45) & 16(57) \\ \text { Mixed } & 2(1.4) & 2(1.8) & 0(0) \\ \text { Shape (mass) } & & & \\ \text { Oval } & 16(22) & 16(26) & 0(0) \\ \text { Round } & 16(22) & 12(20) & 4(33) \\ \text { Irregular } & 41(56) & 33(54) & 8(67) \\ \text { Margins (mass) } & & & \\ \text { Circumscribed } & 34(47) & 30(49) & 4(33) \\ \text { Irregular } & 32(44) & 25(41) & 7(58) \\ \text { Spiculated } & 7(9) & 6(10) & 1(8.3) \\ \text { Enhancement (mass) } & & & \\ \text { Homogeneous } & 33(45) & 29(47) & 4(33) \\ \text { Heterogeneous } & 37(50) & 30(48) & 7(58) \\ \text { Rim enhancement } & 3(4.1) & 2(3.2) & 1(9) \\ \text { Dark internal septation } & 1(1.4) & 1(1.6) & 0(0)\end{array}$

0.7

0.6

0.12
Table 6 (continued)

\begin{tabular}{lllll}
\hline Imaging feature & \multicolumn{2}{l}{ Upgrade status } & \multirow{2}{*}{$p$-value } \\
\cline { 2 - 4 } & Overall & No-upgrade & Upgrade & \\
\hline Focal & $25(37)$ & $22(42)$ & $3(19)$ & \\
Linear & $23(34)$ & $18(35)$ & $5(31)$ & \\
Segmental & $18(26)$ & $11(21)$ & $7(44)$ & \\
Regional & $2(2.9)$ & $1(1.9)$ & $1(6.2)$ & \\
Multiple regions & $0(0)$ & $0(0)$ & $0(0)$ & \\
Diffuse & $0(0)$ & $0(0)$ & $0(0)$ & \\
Enhancement (non- & & & & \\
mass) & & & & \\
Homogeneous & $10(15)$ & $7(13)$ & $3(19)$ & \\
Heterogeneous & $36(53)$ & $28(54)$ & $8(50)$ & \\
Clumped & $22(32)$ & $17(33)$ & $5(31)$ & \\
Clustered rings & $0(0)$ & $0(0)$ & $0(0)$ & \\
DCE (kinetics)* & & & & \\
Progressive & $54(40)$ & $47(44)$ & $7(25)$ & \\
Plateau & $63(47)$ & $47(44)$ & $16(57)$ & \\
\hline
\end{tabular}

$0.2 \quad A D C$ apparent diffusion coefficient, BI-RADS breast imaging-reporting \& data system, $B P E$ background parenchymal enhancement, $D C E$ dynamic contrast-enhanced, DWI diffusion-weighted imaging, $F G T$ fibroglandular tissue

0.6 *Kinetic analysis was performed only by $\mathrm{R} 1$

Table 7 Comparison of clinical and image-guided biopsy technical data between upgraded and no-upgrade patients

\begin{tabular}{lll}
\hline Imaging feature & Upgrade status & $p$-value \\
\cline { 2 - 3 } & Overall No-upgrade Upgrade
\end{tabular}

Associated malig-

0.2

nancy

Contralateral

None

History of breast cancer

Needle caliber

0.9

$9 \mathrm{G}$

$12 \mathrm{G}$

$14 \mathrm{G}$

Size (mm)

$\begin{array}{lll}22(15.8) & 15(13.5) & 7(25) \\ 44(31.7) & 34(30.6) & 10(35.7) \\ 55(39.5) & 48(43.2) & 7(25) \\ 18(12.9) & 14(12.6) & 4(14.2)\end{array}$

No. of specimens

$123(88) \quad 99(89) \quad 24(86)$

$11(7.9) \quad 8(7,2) \quad 3(11)$

$5(3.6) \quad 4(3.6) \quad 1(3.6)$

$15(3-70) \quad 9(3-56) \quad 11(4-70) \quad 0.077$

0.6 Size and number of specimens are reported as median values with associated ranges; all other parameters are presented as frequencies, with percentages given in parentheses for each parameter

0.5 to keep the methodology clear and rely upon real data from the clinic. The features used as input parameters for the predictive models were chosen based on their performance on the entire dataset, and this can introduce bias and overfitting into the model as features have already been filtered to suit the specific dataset. Even with this 
possible overfitting, the AUC values for all models fell below 0.700 and would be described as poor [35], suggesting that there are very weak associations to be made at best.

In conclusion, there does not seem to be enough evidence to suggest that we can predict which high-risk lesions will be upgraded to malignancy based on the radiomic data. Our results show, however, that the number of specimens sampled during image-guided biopsy is associated with the upgrade rate of $\mathrm{ADH}$ at surgical excision.

Acknowledgements Joanne Chin, MFA, ELS, provided editorial assistance for the manuscript.

Author contributions All authors contributed to the study conception and design. Material preparation, data collection and analysis were performed by RLG, KV, CR and PG. The first draft of the manuscript was written by RLG and all authors commented on previous versions of the manuscript. All authors read and approved the final manuscript.

Funding Open Access funding provided by Medical University of Vienna. This work was supported in part through the National Institutes of Health/National Cancer Institute Cancer Center Support Grant P30 CA008748, Breast Cancer Research Foundation, Susan G Komen, Spanish Foundation Alfonso Martin Escudero, and European School of Radiology. The funding sources had no role in the study design; in the collection, analysis and interpretation of data; in the writing of the report; and in the decision to submit the article for publication.

\section{Compliance with ethical standards}

Conflict of interest All authors report no industry support of the project. Katja Pinker received payment for activities not related to the present article including lectures including service on speakers bureaus and for travel/ accommodations/meeting expenses unrelated to activities listed from the European Society of Breast Imaging (MRI educational course, annual scientific meeting). Elizabeth A Morris has received a grant from GRAIL. Maxine S Jochelson has received an honorarium from GE for speaking, and an honorarium for speaking at the Lynn Sage Breast Cancer Symposium and at MD Anderson. The other authors of this manuscript declare no conflicts of interest.

Ethical approval All procedures performed in studies involving human participants were in accordance with the ethical standards of the institutional review board at Memorial Sloan Kettering Cancer Center and with the 1964 Helsinki declaration and its later amendments or comparable ethical standards. This article does not contain any studies with animals performed by any of the authors.

Informed consent This was an IRB-approved and HIPAA-compliant retrospective study for which the need for written informed consent was waived.

Open Access This article is licensed under a Creative Commons Attribution 4.0 International License, which permits use, sharing, adaptation, distribution and reproduction in any medium or format, as long as you give appropriate credit to the original author(s) and the source, provide a link to the Creative Commons licence, and indicate if changes were made. The images or other third party material in this article are included in the article's Creative Commons licence, unless indicated otherwise in a credit line to the material. If material is not included in the article's Creative Commons licence and your intended use is not permitted by statutory regulation or exceeds the permitted use, you will need to obtain permission directly from the copyright holder. To view a copy of this licence, visit http://creativecommons.org/licenses/by/4.0/.

\section{References}

1. Kiluk JV, Acs G, Hoover SJ (2007) High-risk benign breast lesions: current strategies in management. Cancer Control 14(4):321-329. https://doi.org/10.1177/107327480701400402

2. Gulla S, Lancaster R, De Los SJ (2018) High-risk breast lesions and current management. Semin Roentgenol 53(4):252-260. https ://doi.org/10.1053/j.ro.2018.08.001

3. Forester ND, Lowes S, Mitchell E, Twiddy M (2019) High risk (B3) breast lesions: what is the incidence of malignancy for individual lesion subtypes? a systematic review and meta-analysis. Eur J Surg Oncol 45(4):519-527. https://doi.org/10.1016/j. ejso.2018.12.008

4. McGhan LJ, Pockaj BA, Wasif N, Giurescu ME, McCullough AE, Gray RJ (2012) Atypical ductal hyperplasia on core biopsy: an automatic trigger for excisional biopsy? Ann Surg Oncol 19(10):3264-3269. https://doi.org/10.1245/s10434-012-2575-0

5. Margenthaler JA, Duke D, Monsees BS, Barton PT, Clark C, Dietz JR (2006) Correlation between core biopsy and excisional biopsy in breast high-risk lesions. Am J Surg 192(4):534-537. https:// doi.org/10.1016/j.amjsurg.2006.06.003

6. Tsuchiya K, Mori N, Schacht DV, Sheth D, Karczmar GS, Newstead GM, Abe H (2017) Value of breast MRI for patients with a biopsy showing atypical ductal hyperplasia (ADH). J Magn Reson Imaging 46(6):1738-1747. https://doi.org/10.1002/jmri.25694

7. Bedei L, Falcini F, Sanna PA, Casadei Giunchi D, Innocenti MP, Vignutelli P, Saragoni L, Folli S, Amadori D (2006) Atypical ductal hyperplasia of the breast: the controversial management of a borderline lesion: experience of 47 cases diagnosed at vacuumassisted biopsy. Breast 15(2):196-202. https://doi.org/10.1016/j. breast.2005.05.008

8. Sinn HP, Kreipe H (2013) A brief overview of the WHO classification of breast tumors, 4th edition, focusing on issues and updates from the 3rd edition. Breast Care Basel 8(2):149-154. https://doi.org/10.1159/000350774

9. Gradishar WJ, Anderson BO, Balassanian R, Blair SL, Burstein HJ, Cyr A, Elias AD, Farrar WB, Forero A, Giordano SH, Goetz MP, Goldstein LJ, Isakoff SJ, Lyons J, Marcom PK, Mayer IA, McCormick B, Moran MS, O’Regan RM, Patel SA, Pierce LJ, Reed EC, Salerno KE, Schwartzberg LS, Sitapati A, Smith KL, Smith ML, Soliman H, Somlo G, Telli ML, Ward JH, Kumar R, Shead DA (2018) Breast cancer, version 4.2017, NCCN clinical practice guidelines in oncology. J Natl Compr Cancer Netw 16(3):310-320. https://doi.org/10.6004/jnccn.2018.0012

10. Ha R, Mutasa S, Sant EPV, Karcich J, Chin C, Liu MZ, Jambawalikar S (2019) Accuracy of distinguishing atypical ductal hyperplasia from ductal carcinoma in situ with convolutional neural network-based machine learning approach using mammographic image data. AJR Am J Roentgenol. https://doi.org/10.2214/ ajr.18.20250

11. Harrington L, diFlorio-Alexander R, Trinh $\mathrm{K}$, MacKenzie T, Suriawinata A, Hassanpour S (2018) Prediction of atypical ductal hyperplasia upgrades through a machine learning approach to reduce unnecessary surgical excisions. JCO Clin Cancer Inform 2:1-11. https://doi.org/10.1200/cci.18.00083

12. Deshaies I, Provencher L, Jacob S, Côté G, Robert J, Desbiens C, Poirier B, Hogue JC, Vachon E, Diorio C (2011) Factors associated with upgrading to malignancy at surgery of atypical ductal 
hyperplasia diagnosed on core biopsy. Breast 20(1):50-55. https ://doi.org/10.1016/j.breast.2010.06.004

13. Bendifallah S, Defert S, Chabbert-Buffet N, Maurin N, Chopier J, Antoine M, Bezu C, Touche D, Uzan S, Graesslin O, Rouzier R (2012) Scoring to predict the possibility of upgrades to malignancy in atypical ductal hyperplasia diagnosed by an 11-gauge vacuum-assisted biopsy device: an external validation study. Eur J Cancer 48(1):30-36. https://doi.org/10.1016/j.ejca.2011.08.011

14. Ko E, Han W, Lee JW, Cho J, Kim EK, Jung SY, Kang MJ, Moon WK, Park IA, Kim SW, Kim KS, Lee ES, Min KH, Kim SW, Noh DY (2008) Scoring system for predicting malignancy in patients diagnosed with atypical ductal hyperplasia at ultrasound-guided core needle biopsy. Breast Cancer Res Treat 112(1):189-195. https://doi.org/10.1007/s10549-007-9824-0

15. Racz JM, Carter JM, Degnim AC (2017) Lobular neoplasia and atypical ductal hyperplasia on core biopsy: current surgical management recommendations. Ann Surg Oncol 24(10):2848-2854. https://doi.org/10.1245/s10434-017-5978-0

16. Strigel RM, Eby PR, Demartini WB, Gutierrez RL, Allison KH, Peacock S, Lehman CD (2010) Frequency, upgrade rates, and characteristics of high-risk lesions initially identified with breast MRI. AJR Am J Roentgenol 195(3):792-798. https://doi. org/10.2214/ajr.09.4081

17. Liberman L, Holland AE, Marjan D, Murray MP, Bartella L, Morris EA, Dershaw DD, Wynn RT (2007) Underestimation of atypical ductal hyperplasia at MRI-guided 9-gauge vacuumassisted breast biopsy. AJR Am J Roentgenol 188(3):684-690. https://doi.org/10.2214/ajr.06.0809

18. Heller SL, Elias K, Gupta A, Greenwood HI, Mercado CL, Moy L (2014) Outcome of high-risk lesions at MRI-guided 9-gauge vacuum- assisted breast biopsy. AJR Am J Roentgenol 202(1):237-245. https://doi.org/10.2214/ajr.13.10600

19. Weinfurtner RJ, Patel B, Laronga C, Lee MC, Falcon SL, Mooney BP, Yue B, Drukteinis JS (2015) Magnetic resonance imagingguided core needle breast biopsies resulting in high-risk histopathologic findings: upstage frequency and lesion characteristics. Clin Breast Cancer 15(3):234-239. https://doi.org/10.1016/j. clbc.2014.12.005

20. Mann RM, Balleyguier C, Baltzer PA, Bick U, Colin C, Cornford E, Evans A, Fallenberg E, Forrai G, Fuchsjäger MH, Gilbert FJ, Helbich TH, Heywang-Köbrunner SH, Camps-Herrero J, Kuhl CK, Martincich L, Pediconi F, Panizza P, Pina LJ, Pijnappel RM, Pinker-Domenig K, Skaane P, Sardanelli F (2015) Breast MRI: EUSOBI recommendations for women's information. Eur Radiol 25(12):3669-3678. https://doi.org/10.1007/s00330-015-3807-z

21. Mann RM, Kuhl CK, Kinkel K, Boetes C (2008) Breast MRI: guidelines from the European society of breast imaging. Eur Radiol 18(7):1307-1318. https://doi.org/10.1007/s0033 0-008-0863-7

22. Marino MA, Riedl CC, Bernathova M, Bernhart C, Baltzer PAT, Helbich TH, Pinker K (2018) Imaging phenotypes in women at high risk for breast cancer on mammography, ultrasound, and magnetic resonance imaging using the fifth edition of the breast imaging reporting and data system. Eur J Radiol 106:150-159. https://doi.org/10.1016/j.ejrad.2018.07.026

23. Morris EA CC, Lee CH, et al. (2013) ACR BI-RADS® magnetic resonance imaging. In: ACR BI-RADS $\AA$ Atlas, breast imaging reporting and data system. American College of Radiology, Reston, VA

24. Rosset A, Spadola L, Ratib O (2004) OsiriX: an open-source software for navigating in multidimensional DICOM images. J
Digital Imaging 17(3):205-216. https://doi.org/10.1007/s1027 8-004-1014-6

25. Linda A, Zuiani C, Bazzocchi M, Furlan A, Londero V (2008) Borderline breast lesions diagnosed at core needle biopsy: can magnetic resonance mammography rule out associated malignancy? preliminary results based on 79 surgically excised lesions. Breast 17(2):125-131. https://doi.org/10.1016/j.breas t.2007.11.002

26. Pediconi F, Padula S, Dominelli V, Luciani M, Telesca M, Casali V, Kirchin MA, Passariello R, Catalano C (2010) Role of breast MR imaging for predicting malignancy of histologically borderline lesions diagnosed at core needle biopsy: prospective evaluation. Radiology 257(3):653-661. https://doi.org/10.1148/radio 1.10100732

27. Linda A, Zuiani C, Furlan A, Lorenzon M, Londero V, Girometti R, Bazzocchi M (2012) Nonsurgical management of high-risk lesions diagnosed at core needle biopsy: can malignancy be ruled out safely with breast MRI? AJR Am J Roentgenol 198(2):272280. https://doi.org/10.2214/ajr.11.7040

28. Cheeney S, Rahbar H, Dontchos BN, Javid SH, Rendi MH, Partridge SC (2017) Apparent diffusion coefficient values may help predict which MRI-detected high-risk breast lesions will upgrade at surgical excision. J Magn Reson Imaging 46(4):1028-1036. https://doi.org/10.1002/jmri.25656

29. Crystal P, Sadaf A, Bukhanov K, McCready D, O’Malley F, Helbich TH (2011) High-risk lesions diagnosed at MRI-guided vacuum-assisted breast biopsy: can underestimation be predicted? Eur Radiol 21(3):582-589. https://doi.org/10.1007/s0033 0-010-1949-6

30. Lourenco AP, Khalil H, Sanford M, Donegan L (2014) Highrisk lesions at MRI-guided breast biopsy: frequency and rate of underestimation. AJR Am J Roentgenol 203(3):682-686. https:// doi.org/10.2214/ajr.13.11905

31. Gomes DS, Porto SS, Balabram D, Gobbi H (2014) Interobserver variability between general pathologists and a specialist in breast pathology in the diagnosis of lobular neoplasia, columnar cell lesions, atypical ductal hyperplasia and ductal carcinoma in situ of the breast. Diagn Pathol 9:121. https://doi. org/10.1186/1746-1596-9-121

32. Nguyen CV, Albarracin CT, Whitman GJ, Lopez A, Sneige N (2011) Atypical ductal hyperplasia in directional vacuum-assisted biopsy of breast microcalcifications: considerations for surgical excision. Ann Surg Oncol 18(3):752-761. https://doi.org/10.1245/ s10434-010-1127-8

33. Chawla NV, Bowyer KW, Hall LO, Kegelmeyer WP (2002) SMOTE: synthetic minority over-sampling technique. J Artif intell Res 16:321-357

34. Haibo H, Yang B, Garcia EA, Shutao L (2008) ADASYN: adaptive synthetic sampling approach for imbalanced learning. In: 2008 IEEE international joint conference on neural networks (IEEE World Congress on Computational Intelligence), 1-8 June 2008. Pp. 1322-1328. https://doi.org/10.1109/IJCNN.2008.46339 69

35. Hosmer DW Jr, Lemeshow S, Sturdivant RX (2013) Applied logistic regression, vol 398. Wiley, Hoboken, NJ

Publisher's Note Springer Nature remains neutral with regard to jurisdictional claims in published maps and institutional affiliations. 